\title{
PREMARITAL HEALTH SCREENING - A REVIEW AND UPDATE
}

\author{
Rahman $\mathrm{MM}^{1}$, Naznin $\mathrm{L}^{2}$, Giti $\mathrm{S}^{3}$, Islam $\mathrm{MS}^{4}$, Khatun $\mathrm{N}^{5}$
}

\begin{abstract}
Introduction: In Bangladesh among inherited genetic diseases, thalassaemias and haemoglobinopathies are common and cause significant morbidity and mortality and impose a heavy financial burden on our society. Through premarital testing it is possible to reduce the number of children affected with genetic or other blood transmitted diseases.
\end{abstract}

Aim: This review aims to motivate the general populations and reanimate the interest of stakeholders involved in the management of inherited genetic disorders and put forward the recommendations and proposal for implementing premarital screening programmes in Bangladesh.

Materials \& Methods: Relevant literatures were retrieved from different journals and web pages to highlight the definition, advantages and importance of premarital screening, types of investigation in the screening programmes and system of implementing this programme.

Discussion: Review of different literature indicates that premarital screening programme is a complex social, religious and moral issue generating legal concerns regarding the infringement of fundamental liberty, the right to marry and the implications of involuntary withdrawal of blood. In regions where inherited genetic disorders are high, knowledge and outcome of the diseases and uptake of voluntary counseling is low. This is probably because these disorders are greater in developing and under developed countries where literacy and level of understanding are low. Culture and individual attitudes also have a role in the success of testing.
In Asia, voluntary premarital screening programmes began for inherited and sexually transmitted diseases in countries like China, Taiwan, Malaysia, India, Indonesia, Maldives, Singapore and Thailand but no data is available regarding premarital screening programmes in Pakistan, Nepal, Sri Lanka, Bhutan and Bangladesh.

Conclusion: Paucity of resources and trained health professionals in the area of medical genetics are major impediments in implementing premarital screening programmes in Bangladesh. Besides, religious beliefs, cultural norms, social customs as well as illiteracy may be the other barriers in performing the premarital screening programmes in Bangladesh. But it is high time to undertake motivational programmes and pilot projects to implement the premarital screening programmes in order to reduce the inherited genetic disorders, especially thalassaemias and haemoglobinopathies.

Key-words: Premarital screening, Thalassaemia, Haemoglobinopathies, Consanguineous, Genetic.

\section{Introduction}

Premarital Screening (PMS) is defined as a panel of tests in which couples that are going to get married are tested for genetic, infectious and blood transmitted diseases to prevent any risk of transmitting any disease to their children. Nowadays premarital screening is one of the most important strategies for prevention of genetic disorders, congenital anomalies and several medical, psychological marital problems ${ }^{1}$. Premarital Counseling (PMC) is also the most appropriate procedure as it is generally acceptable

1. Col Md Mizanur Rahman, MBBS, MCPS, DCP, FCPS, Classified Specialist in Pathology, AFIP, Dhaka;

2. Major Lubna Naznin, MBBS, MCPS, DCP, FCPS, Graded Specialist in Pathology, AFIP, Dhaka;

3. Col Susane Giti, MBBS, MCPS, FCPS, Classified Specialist in Pathology, AFIP, Dhaka; 4. Maj Gen Md Saiful Islam(Retd), MBBS, MCPS, FCPS, Commandant and Classified Specialist in Pathology, AFIP, Dhaka; 5. Dr Nasima Khatun, MBBS, MPH (RCH), Medical Consultant, Shahriar (Gildan) Fabric Industry Ltd, Ashulia, Savar. 
from the religious and ethnical point of view as well as its minimal health and economical requirements ${ }^{2}$. The majority of counseling concerns haemoglobinopathies (Sickle cell anaemia and thalassaemias). These diseases are a major public health problem in the Mediterranean area, the Middle East, the Indian subcontinent including Bangladesh, South East Asia, tropical Africa and the Caribbean. According to the WHO approximately 250 million people are heterozygous for inherited haemoglobinopathies including thalassaemias and sickle cell disease ${ }^{3}$. In Kingdom of Saudi Arabia (KSA) and other Muslim countries, the pattern of marriage encourages consanguineous and other forms of relative marriages, leading to an increase in the occurrence of recessive genetic disorders ${ }^{4}$. Genetic disorders especially thalassaemias and haemoglobinopathies are highly prevalent in general population of these countries including Bangladesh ${ }^{5}$. Hereditary disease specifically haemoglobin $E$ disease, thalassaemia, double heterozygous haemoglobin E -Beta thalassemia and to a lesser extent haemoglobin $D$ disease or sickle cell disease are present with a high prevalence in South East Asia including Bangladesh and cause greater suffering of the population in these areas ${ }^{6}$.

Since 1972, Bangladesh has made progress in some health related aspects such as infant mortality, life expectancy and access to health care but lacking far behind in providing genetic services from many of the countries including our neighbouring country, India. Data from industrialized countries show that significant genetic diseases or birth defects that may affect approximately $3 \%$ of all pregnancies, account for up to $30 \%$ of paediatric hospital admissions and cause about $50 \%$ of childhood deaths. In addition recessively inherited disorders account for less than $20 \%$ of single gene disorders and less than $5 \%$ of congenital and genetic diseases. On the other hand, genetic and congenital disorders are responsible for a considerable proportion of perinatal and neonatal mortalities in the world ${ }^{7}$. Effective prevention can maximize the available resources if it is instituted properly, preventing up to $95 \%$ of affected births. Healthy carriers of beta-thalassaemia can be identified inexpensively and accurately by a simple blood test. Couples who undergo testing can be informed about genetic risks and given option for reducing risk, including prenatal diagnosis ${ }^{8}$.

\section{Background}

Initial thalassaemia screening was first carried out in 1975 by Silvestroni and colleagues in Latium, Italy, as part of school prevention programme ${ }^{9}$. Screening for sickle cell anaemia began before this, in Virginia ${ }^{9}$ in 1970. Nationwide screening programmes also began in Canada, Cyprus, Greece, Italy and the UK during the 1970 s, with proven success ${ }^{10}$. Until this point, the genetic causes of haemoglobinopathies were understood but little had been done to prevent them in newborns ${ }^{11}$. The commencement date of premarital screening programmes with type of investigation is shown in table--12-17.

Global aspects of premarital screening programmes: Premarital testing programmes should also educate couples, providing accurate and unbiased information. They should be available to anyone who want them and proper diagnostic techniques must be used ${ }^{18}$. Informed consent is necessary, as well as guarantees of privacy and treatment of the affected individuals. Premarital programmes are most successful when social, religious, ethnic and cultural factors are all addressed ${ }^{8}$. Angastiniotis and Modell ${ }^{19}$ classified countries who deliver premarital screening programmes into three categories:

1. Endemic Mediterranean countries in which preventive programmes are long-established, with success rate (preventive) of $80-100 \%$ and optimum treatment via specialist clinics.

2. Developed, industrialized countries in which prevalence is increasing because of migration; these countries can fund screening programmes, but find it difficult to reach immigrants with certain cultural backgrounds.

3. Developing countries in which there are economic difficulties and other health priorities (e.g. infectious disease control) or other religious or cultural constraints $^{19}$.

In Cyprus, Greece and Italy, premarital screening for thalassaemia has been normal practice for a long time as because of high consanguinity. Similar preventive programmes have been introduced in Bahrain, China, India, the Islamic Republic of Iran, Indonesia, Malaysia, the Maldives, Singapore and Thailand, and recently in Saudi Arabia and United- 
Arab emirates. In the UK, Northern Ireland and other Northwest European countries, prenatal diagnosis is available and abortion is a prevention stratagey ${ }^{8}$. In china, couples who wish to marry are extensively tested, including physical examination. They are given premarital health instructions and 'counseling' - in the form of watching videotapes of the type of child they may conceive - after which appropriate measures are taken. This approach has been strongly criticized in terms of human rights, control, oppression and eugenics, even though the value of vigilant premarital screening is acknowledged ${ }^{20}$. In Lebanon, thalassaemia patients are managed in chronic-care centres in collaboration with the ministries of Social Affairs and Public Health. These screening programme provide information, train health professionals and develope training materials with priority given to disseminating knowledge and public awareness ${ }^{21}$. Tosun et al studied the premarital haemoglobinopathies screening programmes in Mersin, Turkey, where consanguinity is $30 \%$. If the man and the woman are both carriers, results are given confidentially and they are counseled about their options, including prenatal diagnosis ${ }^{11}$. In Saudi Arabia, premarital testing for haemoglobinopathies is mandatory. The results of at-risk couples are treated in the same way as in Turkey, prenatal diagnosis is not offered ${ }^{22}$.

\begin{tabular}{|c|c|c|}
\hline Country & Date started & Type of screening \\
\hline Italy & 1975 & Thalassaemia (mandatory) ${ }^{9}$ \\
\hline Bahrain & 1985 & Thalassaemia and sickle cell disease (mandatory) $^{12}$ \\
\hline Iran & 2004 & Thalassaemia (mandatory) $^{13}$ \\
\hline Jordan & 2004 & Thalassaemia (mandatory) ${ }^{14}$ \\
\hline Saudi & 2004 & Thalassaemia and sickle cell disease (mandatory) ${ }^{7}$ \\
\hline Arabia & 2008 & HIV, HVB and $\mathrm{HCV}^{15}$ \\
\hline United Arab Emirates & 2007 & Thalassaemia (mandatory) $^{8}$ \\
\hline Tunisia & $t$ & Thalassaemia (mandatory) $^{9}$ \\
\hline Egypt & $t$ & Thalassaemia and STDs (voluntary) $)^{9}$ \\
\hline Spain & $\dagger$ & Thalassaemia and STDs (voluntary) $^{9}$ \\
\hline Portugal & $t$ & Thalassaemia and STDs (voluntary) ${ }^{9}$ \\
\hline $\begin{array}{l}\text { Turkey } \\
\text { Merlin } \\
\text { Denizlin }\end{array}$ & $\begin{array}{l}1998 \\
1995\end{array}$ & $\begin{array}{l}\text { Thalassaemia (mandatory) } \\
\text { Thalassaemia (voluntary) }\end{array}$ \\
\hline Cyprus & 1973 & Thalassaemia (mandatory) 11 \\
\hline Canada & 1970s & Thalassaemia, SCD \& STDs (voluntary) $)^{3}$ \\
\hline Greece & 1975 & Thalassaemia (voluntary) 3 \\
\hline UK & 1970s & Thalassaemia, SCD \& STDs (voluntary) $^{3}$ \\
\hline USA, Illinois \& Louisiana & 1983 & STDs including HIV (mandatory), stopped ${ }^{16}$ \\
\hline China & 1992 & Inherited diseases, HBV \& HIV (mandatory till 2003) \\
\hline Taiwan & 1993 & Thalassaemia (voluntary) $^{12}$ \\
\hline Brazil & $\dagger$ & Inherited \& STDs (mandatory in some areas) ${ }^{9}$ \\
\hline Palestine & $\dagger$ & Thalassaemia (mandatory) $^{8}$ \\
\hline Malaysia, Johor & 2002 & HIV (mandatory) ${ }^{13}$ \\
\hline India & $\dagger$ & Inherited \& STDs (voluntary) ${ }^{17}$ \\
\hline Indonesia & $t$ & Inherited \& STDs (voluntary) \\
\hline Maldives & $\dagger$ & Inherited \& STDs (voluntary) $)^{17}$ \\
\hline Singapore & $t$ & Inherited \& STDs (voluntary) ${ }^{17}$ \\
\hline Thailand & $t$ & Inherited \& STDs (voluntary) $)^{17}$ \\
\hline
\end{tabular}


Role of Culture and Education in the success of premarital screening programmes: 'Consanguinity' refers to relationship by blood or common ancestry, in which the chances of inheriting a recessive disease are increased; the closer the relationship the greater the risk. Marriages between same tribes or extended family groups are favoured in some cultures, including those between first cousins. Consanguineous marriages are uncommon in Western countries. Marriage between first cousins is forbidden by the Orthodox Church and Roman Catholic Church, and may be seen as incestuous in the United States ${ }^{11}$. Personal characteristics including socioeconomic status have implications for the outcome of premarital screening programmes. Education of the couples who are to be screened is extremely important and it is important to educate all members of the screening team (laboratory technologists, nurse practitioners, physicians, counselors, outreach workers and social workers). According to Schmidt, 'sufficient planning in the educational area before the first blood sample is drawn can avoid failures of the programme ${ }^{23}$. The meaning of the term 'carrier status' should be made known to members of the public long before they get married. For successful public education, government and government organizations must cooperate, as well as community and religious leaders, school parent organizations and health personnel ${ }^{11}$.

People who responded to information about premarital screening had favourable attitudes towards premarital counseling and examination of consanguineous marriages, possibly relating to social changes, declining illiteracy, increasing economic pressures, increasing numbers of nuclear families and longer waiting times before starting a family. People with a negative attitude towards these tests were mostly unmarried males. Eshra and colleagues suggested educational programmes about the benefits of premarital examination should target unmarried males, so they can make informed choices about unmarried females and consanguineous marriages ${ }^{24}$. Religious beliefs restrict the success of screening programmes in some communities. In southern Iran, premarital screening has been made mandatory for 10 years, yet high-risk couples still get married and give birth to children homozygous for beta-thalassaemia. Often this is because of religious and traditional cultural restraints; in the case of Islam, consanguineous marriages are permitted, so thalassaemia persists in some parts of the community, making the programme redundant ${ }^{25}$. Some people believe that their fate is determined by God and therefore accept the risk of having a sick child. A recent report in The Jordan Times showed that many Jordanians view the results of their 'unions' as fate ${ }^{26}$. One interviewee stated: 'All my ten children are disabled; they will get their reward in haven'. On the contrary, there are many teachings in the Islamic culture that promote healthy marriage and the role of counseling ${ }^{27}$. AlKhaldi et al evaluated the attitude of health-science students in Saudi Arabia towards premarital screening and counseling. Most students had a positive attitude, but around $25 \%$ refused testing and counseling according to their interpretation of Islamic principles ${ }^{28}$. Awatif studied attitudes among female students in King Saud University, discovering that $86 \%$ of them felt positively about premarital testing ${ }^{29}$. El-Hazmi assessed attitudes in a community-based study and found $94 \%$ of participants considered premarital testing and counseling to be important in preventing genetic diseases; $87 \%$ thought testing should be mandatory. The Saudi community clearly shows awareness of premarital testing and its value ${ }^{2}$; however when Al Hamdan et al studied the outcome of the first 2 years of the Saudi screening programmes, they found that about $90 \%$ of high-risk couples still got married despite knowing their risk of having a sick child. This undermines the high level of awareness identified in other studies ${ }^{22}$. One possible explanation is that both $\mathrm{Al}$ Haldi et al and Awatif focused on the options of university students ${ }^{28,29}$. Reports by Karimi et al, Monaghan and AlKhaldi et al were from three different Islamic countries, and all three provided evidence that religious beliefs could be obstacles to the success of premarital screening programmes, regardless of other factors such as education level ${ }^{25,26,28}$. The same conclusions were reported long ago in other (non-Muslim) communities. In 1981, Angastiniotis and Hadjiminas stated that support from the Church was the main reason for the success of screening programmes in Cyprus and Greece ${ }^{30}$.

Premarital screening programmes in Asia and Indian Subcontinent: In Asia, voluntary premarital screening programmes began for inherited and sexually transmitted diseases in countries like China, Taiwan, Malaysia, India, Indonesia, Maldives, Singapore and Thailand ${ }^{8}$. 
No data is available regarding premarital screening programmes in Pakistan, Nepal, Sri Lanka, Bhutan and Bangladesh. In India, a few selected private clinics are offering premarital screening testing as a package ${ }^{31}$. In Bangladesh, Pakistan, Nepal, Bhutan and Sri Lanka as well as in India, the health related problems including inherited diseases are more prevalent, so the governments of these countries should be committed to solve these problems. They are engaged to prevent the communicable and other chronic diseases. Although the governments of these countries are aware of the high prevalence of inherited and sexually transmitted diseases but because of economic constraints, they focus their attention to more common and easily preventable diseases. As the time passes, gradually these countries are achieving economic solvency and time has come to give proper attention to prevent inherited diseases. Haemoglobinopathies and beta-thalassaemia are more prevalent in these countries, so necessary measures and action plan should be formulated to reduce the incidence of these inherited diseases.

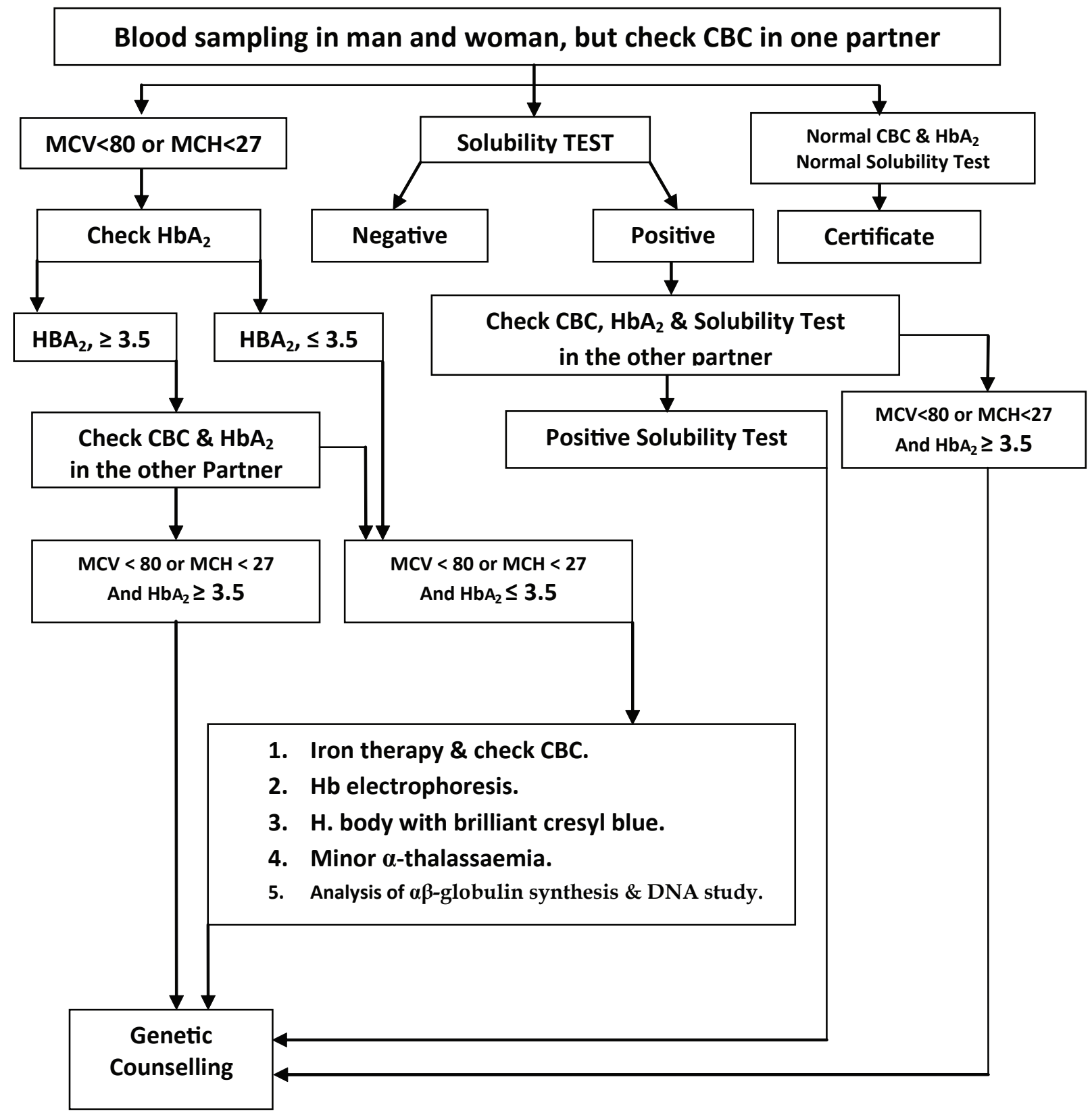

Fig -1: Recommended premarital screening programme. 


\section{Counseling}

Genetic counseling is the process by which an individual or a family obtains information about a genetic condition that may affect them, so that they can make appropriate decisions about marriage, reproduction and health management ${ }^{27}$. Genetic counseling protects the autonomy of the couple, fulfilling their right to be fully informed about the disorder and all valuable options ${ }^{17}$. Although premarital tests for haemoglobinopathies are reliable and useful, not everyone with these genes responds to counseling. Neal-Cooper and Scoot ${ }^{10}$ reported that young couples concerned about producing a child with sickle cell disease are often offset by their strong desire to have children regardless of risk. The researchers suggested that at-risk couples should be contacted directly by counselors and encouraged to undertake education and counseling. Prevention and treatment of genetic diseases are virtually impossible ${ }^{15}$.

One successful approach is 'solution-focused' premarital counseling. Murray and Murray discuss how this focuses on a couple's resources, helping them to develop a shared vision for the marriage. Background information about premarital counseling and solution-focused therapy provide a framework in which intervention strategies in those confined with positive status for a disease can be developed. These solution- oriented interventions include solution-oriented questions and feedback, as well as a Couple's Resource Map (CRM) which depicts the support available to the couple from various personal relationships and contextual resources ${ }^{32}$. The available choices include avoidance of marriage, reproductive options for those who proceed with the marriage following prenatal diagnosis, adoption of the affected child, donation of sperm, ova or a pre-embryo from an unaffected individual and pre-implantation diagnosis ${ }^{33}$.

Choosing the best option depends on availability, cost and local regulations and religious rules. For example, in Saudi Arabia and most other Muslim countries abortion is prohibited on religious grounds and prenatal diagnosis is useless because abortion is forbidden unless the fetus is malformed. However, pre-implantation diagnosis is permitted and affordable ${ }^{34}$. Thus the success of genetic counseling depends on the approach adopted by the counselor as well as the education and attitude of the couple. Screening programmes must be equitable, accessible and understood by the target population, but most importantly they must comply with the prevailing cultural, ethnic, economic and social values. In Bangladesh, there is still no recognized genetic centre where appropriate genetic counseling facility is available.

\section{Conclusion}

Inherited genetic disorders, especially thalassaemias and haemoglobinopathies are common, incurable, autosomal recessive haemoglobin disorders that cause significant morbidity and mortality and impose a heavy financial burden on society. A simple blood test like estimation of Mean Red Cell Corpuscular Volume (MCV) before marriage can easily detect carriers of these diseases. Premarital health screening is done to inform couples about their chances of producing affected children and ensure they receive appropriate advice.

Premarital screening programmes have become widely accepted and highly valued in preventive health care so much that many countries have made them mandatory. Some very strong social factors influence the acceptability of preventive programmes; among them are the religious beliefs, cultural norms, literacy and education level, government policies and the attitudes of the individual couples. Scientists, medical personnel, politicians, intellectuals, religious motivators, teachers and leaders, socio-cultural organizations and activists, law and policy makers should extend their hands to motivate the peoples about premarital screening testing and help to formulate legislation for premarital screening programme and to implement it in the country. Journalists of electronic and mass media and newspapers as well as physicians, midwives, genetic counselors and clinical laboratory scientists involved in pre-conceptional or prenatal care can play a vital role in developing awareness among the people especially prospective life partners regarding premarital screening programmes. 


\section{References}

1. Al Sulaiman A, Sulaiman A, Al Mishari M, Al Sawadi A, Owaidah TM. Knowledge and attitude toward the hemoglobinopathies premarital screening program in Saudi Arabia: Population-based survey. Hemoglobin 2008; 32 (6): 531-8.

2. El-Hamzi MA. Pre-marital examination as a method of prevention from blood genetic disorders. Community views. Saudi Med J 2006; 27(9): 1291-5.

3. WHO. Hereditary anaemia: genetic basis, clinical features, diagnosis and treatment. Bull World Health Organization 1982; 60: 643-60.

4. Mitwally HH, Abd El-Rahman DA, Mohammad NI. Premarital counseling: view of the target group. J Egypt Public Health Assoc 2000; 17 (1): 31-51.

5. WHO. Hereditary anaemia: memorandum from a WHO meeting. Bull World Health Organization. available at http://www.ncbi.nlm.nih.gov/pmc/articles/PMC2536044/

6. World Health Organization. Health impact assessment (HIA); 2005. Available at: www.who.int.

7. Alwan A, Modell B. Community Control of Genetic and Congenital Disorders, EMRO Technical Publications 24, World Health Organization, 1997.

8. WHO Secretariat Report. Thalassaemia and other haemoglobinopathies. Provisional agenda item 5.2, EB 118 (5). Geneva: World Health Organization 2006.

9. Silvestroni E, Bianco I, Graziani B, Carboni C, D'Arca SU. First premarital screening of thalassaemia carriers in intermediate schools in Latium. J Med Genet 1978; 15: 202-7.

10. Neal-Cooper F, Scott RB. Genetic counseling in sickle cell anaemia: experiences with couples at risk. Public Health Rep 1988; 103: 174-8

11. Tosun F, BilginA, Kizilok A. Five year evaluation of premarital screening program for haemoglobinopathies in the province of Mersin, Turkey. Turk J Hematol 2006; 23: 84-89.

12. Al-Arrayed SS. Review of the spectrum of genetic diseases in Bahrain. Eastern Mediterranean Health Journal 1999; 5: 1114-20.

13. Samavat A, Modell B. Iranian national thalassaemia screening programme 2004. BMJ 329:1134-1137.

14. Hamamya H, Al-Hatib S, Alwanc A, Ajlounia K. Jordan: Communities and community genetics. Commun Genet 2007; 10:52-60.

15. Kuliev AM, Modell B. Problems in the control of genetic disorders. Biomed SCi 1990; 1:3-17.

16. Naylor EW. Genetic screening and genetic counseling: knowledge, attitudes and practices in two groups of family planning professionals. Soc Biol Winter 1975; 22: 304-14.

17. Al-Arrayed SS, Hafadh N, Al-serafi S. Premarital counseling: an experience from Bahrain. East Meditter Health J 1997; 3(3): 415-9.
18. Schumm WR, West DR. Development of three new scales for assessing client's perspectives on premarital counseling. Psychol Rep 2002; 88: 1071-4.

19. Angastiniotis M, Modell B. Global epidemiology of hemoglobin disorders. Ann NY Acad Sci 1998; 850: 251-69.

20. Therese H. Getting married in china: Pass the medical first. BMJ 2003; 326:277-9.

21. Inati $A$, Zeineh $N$, Ismaeel $H$. Beta-thalassaemia: the Lebanese experience. Clin Lab 2006; 28: 217-27.

22. AlHamdan NA, AlMazrou YY, AISwaidi FM, Choudary AJ. Premarital screening for thalassaemia and sickle cell disease in Saudi Arabia. Genet Med 2007; 9: 372-7.

23. Schmidt RM. Haemoglobinopathy screening: approaches to diagnosis, education and counseling. Am J Publ Hlth 1974; 64: 799-804.

24. Eshra DK, Dorgham LS, el-Sherbini AF. Knowledge and attitudes towards premarital counseling and examination. $J$ Egypt Publ HIth Assoc 1989; 64 (1/2): 1-15.

25. Karimi M, Jamalian N, Yarmohammadi H, Askarnejad A, Afrasiabi A, Hashemi A. Premarital screening for beta-thalassaemia in Southern Iran: option for improving the programme. J Med Screen 2007; 14: 62-66.

26. Monaghan S. Genetics: for better or for worse. Middle East Health 2007; 19-26. Available at: http://216.236.204.101/mehealth/sep03_article.pdf(last accessed November 2008).

27. Albar MA. Counseling about genetic disease: an Islamic perspective. East Mediterr Hlth J 1999; 5: 1129-33.

28. AlKhaldi YM, Al-Sharif Al, Sadiq AA, Ziady HH. Attitudes towards premarital counseling among students of Abha Health Sciences College. Saudi Med J (Aug 2002); 23: 986-90.

29. Awatif A. Perception of female students of King Saud University towards premarital screening. J Fam Commu Med 2006; 13: 83-8.

30. Angastiniotis MA, Hadjiminas MG. Prevention of thalassaemia in Cyprus. Lancet 1981; 1: 369-71.

31. Colah R, Surve R, Wadia M, Solanki P. Genetic Testing. June 2008, 12 (2): 181-5.

32. Murray CE, Murray TL Jr. Solution-focused premarital counseling: helping couples build a vision for their marriage. $\mathrm{J}$ Marital FamTher 2004; 30: 349-58.

33. Christine EM. Couples Resource Map Scales study. University of North Carolina (USA). Available at: http://www. couplesresourcemap.org/ (last accessed November 2008).

34. Monaghan S. Genetics: For better or for worse. Middle East Health 2007: 19-26. Available at: http://216.230.204.101/mehealth/sep03_article 1.pdf (last accessed last November 2008). 